\title{
SR2.0: An erroneous argument from genetics which inadvertently refines scientific racism
}

\begin{abstract}
SR2.0 refers to a prominent argument made by some geneticists, often via social and popular media, which inadvertently amounts to a refinement of scientific racism. At face value it is an attack on racism. Upon closer inspection its primary, possibly unconscious, purpose appears to be to protect contemporary genetic research from the charge of racism. The argument is often made alongside an emphasis upon long-falsified errors of early science and open expressions of racism in wider society, rather than the intelligence and statistical theory which has informed both genetics and the social construct scientific racism for a century. The core argument is invalid. It also has profound epistemological failings, including misunderstanding the nature of social constructions and how they how they interact with empirical facts. Finally, the proponents do not fully support their own argument; this exposes the argument's substantive function as a defensive holding device.
\end{abstract}

\section{Background}

Behavioural geneticists are linking, with increasing specificity, sub-gene genetic material to individual educational outcomes $(1,2,3,4)$. UK-based Professor Robert Plomin has proposed the "personalisation" of education as informed by the DNA and IQ testing of children (5,6). This proposal, and the science behind it, has received interest at the highest levels of the UK government via Dominic Cummings, presently the UK prime minister's chief adviser $(7,8)$.

The same research nexus is informing other, further-horizon, technological innovations with potentially similar purposes. These include embryo selection $(7,9)$ and "germline" genetic manipulation $(7,10)$.

The application of such ideas in any form would require policymakers to first make judgements around societal and political risk. Concern about social determinism, misplaced or otherwise, is often mentioned in this context $(11)$.

It is at least plausible, however, that the qualified application of genetic research to education, for example to identify and help children born with otherwise debilitating learning difficulties $(12,13)$ could in due course command public support.

Public support for innovative technology with potentially far-reaching social implications is invariably contingent upon rules designed to prevent harm to people, society and the wider field of research $(14,15)$. It is reasonable to infer that a framework for the application of genetic research to education would require risks to be addressed frankly and transparently.

\section{The 'scientific racism' risk}

Scientific racism, the use of scientific method to justify notions of racial superiority, represents a potential hazard to the social application of genetic research. This risk extends from intelligence theory and associated statistical concepts.

Behavioural geneticists explore, amongst other things, human trait variation. In common with scholars and professionals across many fields including marketing and advertising, they 
employ intelligence theory and related statistical methods $(16,17,18)$. Prominent methodologies include twins studies (19) and, more recently, Genome Wide Association Surveys (GWASs) (20).

Inter-racial trait variation is small by comparison both with intra-racial variation and other causes of human variation (21). It is a contentious area of study with little apparent scope for application. Most scholars applying intelligence theory work in other areas likely to yield useful results. These include the study of cognitive degeneration in old age (22) and, at the other end of the spectrum, Plomin and others' early identification of learning difficulties (23).

It is, however, a matter of scholarly and professional orthodoxy that on average people who self-define as black score lower, arguably significantly so, than white in psychometric tests for general intelligence, or ' $\mathrm{g}$ ' (24); and that this helps explain educational and social inequality $(16,25)$. This presents a risk that the application of genetics to public policy, including education, could have racial implications.

SR2.0, outlined below, attempts unsuccessfully to deal with this risk. It fails on its own terms, but also amounts to a refinement of the scientific racism it ostensibly criticises and therefore has the potential to harm.

\section{SR2.0}

This comprises a central argument supported by what appears to be unstated, or unconscious, intentions amongst its proponents. The argument is promoted by geneticists and journalists. It has informed a BBC series (26), newspaper articles (27), and blogs (28). It is the subject of a much-publicised forthcoming popular book by a public scientist and broadcaster entitled; "How to argue with a racist" (29), which has been presaged by a keynote lecture with the same title (30). The central argument may be summarised in brief as the following assertions:

Scientific racism is defined or substantially characterised by the claim that trait variation, notably in respect of general intelligence, between human racial groupings has a biological basis. It is rooted in very early scientific error and current 'pseudoscience'. Like racism, race is a social construct. Observed trait variation, such as in intelligence, between selfdefining racial groupings is a function of environment alone. Scientists can be trusted not to tolerate or apply scientific racism.

This argument seems intended to combat racism in science. However, the structure of the central argument and the way it is supported indicates its substantive function lies elsewhere. For brevity, two points are noted here.

\section{The argument is invalid}

SR2.0 asserts that 'race' and 'racism' are social constructs (31), but also insists the claim of genetic heredity in inter-racial trait variation is a definitive or necessary component of scientific racism (32). These two main premises are incompatible, so the argument is a contradiction fallacy. The scientific notion that white people are on average more intelligent than black is routinely used to justify racial inequality, for example in access to selective schools. Many consider this and the related use of psychometric testing for the purpose of selection to be racist $(33,34)$. It is certainly scientific. It is not open to scientists who accept race 
and racism as social constructs to determine which science is included within the ambit of scientific racism, and which is not.

\section{The argument's proponents do not fully support it}

In a recent keynote lecture self-entitled; "How to argue with a racist", geneticist and science journalist Adam Rutherford says:

"Would it make any difference, if we, as scientists, as honest brokers, did demonstrate that there was a significant biological basis for intelligence or for sporting success that did coincide accurately with folk descriptions of race? If we could do those things, which I think are highly unlikely, but we don't know, I think are highly unlikely, would that mean that we would treat anyone differently?" (bold reflects verbal emphasis in lecture) (35).

With; "we don't know", Rutherford emphasises that scientists including him "don't know" whether or not there is a genetic basis to inter-racial trait variation, in spite of this being ostensibly the central assertion of his argument.

This acceptance of the scientific contestability of the absence or presence of genetic influence upon inter-racial trait variation is present across SR2.0.

For example, an extensive blogpost co-authored by Rutherford, two geneticists and an anthropologist is billed as an "explainer" in effect refuting "pseudoscience" (28). In fact, in the text they do not attempt any such refutation. The post comprises warnings about the limitations of genetic research to date, which can be read both ways, and a plausible case for why it is likely that inter-racial trait variation is not influenced by genetics. But at every turn the authors use soft terms designed to leave the question open.

"for most traits, including IQ, it is not only unclear that genetic variation explains differences between populations, it is also unlikely".

"It is our contention that any apparent population differences in IQ scores are more easily explained by cultural and environmental factors than they are by genetics".

"A plausible argument for the putative lower average IQ score".

The authors make careful use of the qualified language of the untested hypothesis; "unlikely", "unclear", "it is our contention"; "more easily explained by", "a plausible argument". This appears designed to signal acceptance of the potential presence of credible rival scientific theories.

Yet the post attacks scientific opponents in emotional and unscholarly terms; "pseudoscience", "darker currents", "semblance of science", "technical-seeming", "misleading", "distorted science". With unintended irony, the blogpost specifically attacks "a cottage industry" for publishing peer-reviewed scientific papers.

Why do these experienced and socially well-intentioned, liberal and anti-racist scientists present an argument of elementary logical invalidity? Why do they confidently criticise rival theorists in highly personalised terms (i.e. imply, correctly or not, that they are racist) then 
quietly play down their confidence in their own central argument? A poor understanding of epistemology seems one cause; an unstated or unconscious purpose the other.

\section{Epistemology}

Friedrich Hayek popularised the term "scientism" ${ }_{(36,37,38)}$ to describe the inappropriate use of scientific method. At the core of this notion is the nature and function of social constructions. Scientism entails regarding social constructions as lesser or even irrelevant forms of knowledge compared to that arrived at through scientific method. Karl Popper and others developed post-positivism as a means of placing empirical reality into its socially constructed context (39). This is the subject of an extensive literature.

A topical example might be that the existence of a narwhal tusk can be tested empirically and described in every way. It is a sensory organ; unless it is wielded post-mortem by a human to attack a terrorist, in which case it is very much a weapon (40). The weapon is a social construction, but no less real in the lived experience of the terrorist for it.

However, in an article written after he had fronted a BBC series on the subject (27), Rutherford's concluding paragraph begins:

\section{"Race doesn't exist. Racism does. But we can now confine it to opinions".}

In the first sentence, Rutherford argues that race does not exist because it is a social construct, while racism does exist because it is a social construct. The sentence is incoherent, of course, but hints at what is at the core of SR2.0; that is revealed in the second sentence.

SR2.0 wishes to relegate race as knowledge while reducing racism to simply an opinion. The aim seems at face value an anti-racist one, but this relegation is scientistic and fallacious. It also reduces to absurdity a profound and very real phenomenon which impacts daily the lives of many millions of people. Racism is structural and embedded in language, including within science; for people affected it is every bit as real as a small lead projectile flying towards them at high speed.

This subordinating of the social constructs 'race' and 'racism' to empirically-discovered facts is essential to SR2.0 and indeed reveals its substantive function. This is to protect the application of genetic research by narrowing the definition of scientific racism, thereby excluding almost all claims of racism from its ambit. At a linguistic stroke, it makes scientific racism disappear from "mainstream" genetics. Almost all the constituent parts of scientific racism pass through this assumed definition like milk through a sieve. A remnant may not pass for now, but there is no true filtration process and even that remnant may make its way through in the end.

SR2.0's epistemological weakness even reduces its reliability as a guide to the state of genetic science. It argues that genetics is going through accelerated change and some of the science which previously underpinned scientific racism has been controverted. This is true. But it also accepts that many other variables remain in the air.

And since SR2.0 accepts the existence of trait patterns within populations at some level, it is theoretically possible, again because of the constructed nature of race, for some theorists to adjust their use of the term. There are scientific, epistemological and philosophical arguments 
to be had here, for sure. This is why a mechanism for transparent discourse is essential. The alternative is to do as SR2.0 seeks to; with the stroke of a pen, confine discourse to secrecy, denial and proxy terms.

It is unscientific to seek to railroad science with an un-scholarly media campaign and the claim of a special right to define the meaning of the social construction 'race'. Where this is done in the name of anti-racism and liberalism, its unscientific nature in the end provides grist to the mills of racism and illiberalism.

\section{Discussion}

Scientists employing scientific method cannot, by definition, be sure their results will not clash with social constructs such as racism and social determinism. However, it is an epistemological error to argue that this provides an avenue for a scientific justification of racism. The progress of science takes place in conjunction with the constructions scientists interact with and the categories they create. The language they use and the applications they seek for their discoveries are part of these constructions. As with all scholarly work, racism is found here and so it is here it must be engaged.

Scientists can of course help mediate clashes between their work and widely held moral or social imperatives, such as the need to combat racism, but only by respecting the status of non-empirical knowledge and the epistemologies which enable inquiry into them. Scientism is the enemy of this.

For example, the genetics scholarship of Plomin and others are potentially of great public value. However, they contain a number of potential hazards in the application. These include that the underlying theory supports notions that white people are on average of superior intelligence to black, and that this helps explain racial inequality. While such theories are in widespread scholarly and professional use, to many members of society they amount to scientific racism.

But it may well be that this scholarship can be applied in qualified ways which delivers benefit and is assuredly not racist. My own view is that that where medical diagnoses apply, aspects of the genetic research of Plomin and others may be capable of application to education shorn of the taint of scientific racism. This will turn most on the views of those affected by racism, again because of the its constructed nature. It follows that policymakers and geneticists will need to engage in full and transparent dialogue on the subject with those most affected by racism.

SR2.0 is, instead, an incoherent ill-conceived defence of science through a liberal attack on racism fatally flawed by its hidden agenda. Upon inspection, it emerges as a refinement of the very notion it seeks to invalidate. Rhetorically, it fires up the chaff of ancient and longrejected proto-science in order to obscure the role of the still-orthodox intelligence and statistical theory sustaining both important scholarly inquiry and scientific racism for over 100 years.

SR2.0 accepts the average general intelligence superiority of white people over black. It agrees that this helps explain racial inequality. It accepts that intelligence is heritable within groups. It accepts that ethnic patterns exist in trait heritability. It invites judgement on the environmental choices disadvantaged black people make. It even accepts that there may be a 
genetic basis to inter-racial variation. Its error lies not in claiming that these notions have scientific underpinning per se, but in assuming that they cannot at the same time be expressions of the social construction racism. Or, put more constructively, SR2.0 is an expression of a failure by some anti-racist geneticists to understand how the application of science is immeasurably aided through respect for other epistemologies.

SR2.0 is primarily projected through social and popular media rather than scholarly papers. Proponents make eye-catching statements criticising $19^{\text {th }}$ century scientists and contemporary racism in society, and criticise other scholars around the notion of genetic influence, but in the text their arguments are quietly very heavily caveated. The argument fails on its own terms and presents a risk of harm to those many people affected by racism. It is an Olympian case of the scientific overreach Hayek warned of. Its advice about; "How to argue with a racist" is, in the end:

Tell them it is true that self-defining white people have on average higher general intelligence than self-defining black and that this helps explain racial inequality, that heritable trait patterns do exist within populations but these don't perfectly correlate to what we presently call races and that intelligence and other traits are heritable within groups. But also tell them that this probably doesn't explain the differences between racial groups; although, admittedly, it might because we don't know. But in any case, stress that whatever science turns up, it's wrong to treat people unequally on the basis of perceived racial traits.

This might be better entitled; 'How not to argue with a racist.

Instead, those looking for clues about how to actually recognise and argue with racism may

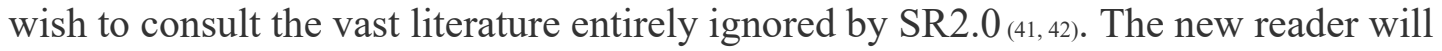
discover that this literature goes well beyond the elementary observation made by SR 2.0 that power lies behind the imposition of racial categories and racial injustice, to the presence of racism in the constructions around scientific and non-scientific scholarship.

Asking a geneticist friend for advice on a marital problem need not involve being told that the first thing you must understand is love and marriage are not empirical realities, and so are of second order importance at best: SR2.0 does its best to make it seem like it might.

Notes and references:

1. Malanchini, M., Rimfeld, K., Wang, Z., Petrill, S.A., Tucker-Drob, E.M., Plomin, R. and Kovas, Y., 2019. Genetic factors underlie the association between anxiety, attitudes and performance in mathematics. bioRxiv, p.719393.

2. Ayorech, Z., Plomin, R. and von Stumm, S., 2019. Using DNA to predict educational trajectories in early adulthood. Developmental psychology.

3. Selzam, S., Krapohl, E., von Stumm, S., O'Reilly, P.F., Rimfeld, K., Kovas, Y., Dale, P.S., Lee, J.J. and Plomin, R., 2017. Predicting educational achievement from DNA. Molecular psychiatry, 22(2), p.267 
4. Krapohl, E. and Plomin, R., 2016. Genetic link between family socioeconomic status and children's educational achievement estimated from genome-wide SNPs. Molecular psychiatry, 21(3), p.437.

5. https://www.tes.com/news/base-education-around-pupils-geneticsschools-advised [retrieved 20 Jan 2020]

6. https://theconversation.com/your-genes-can-help-predict-how-wellyoull-do-in-school-heres-how-we-cracked-it-62848 [retrieved 12 Jan 2020]

7. https://dominiccummings.com/tag/plomin/ [retrieved 20 Jan 2020]

8. https://www.independent.co.uk/news/education/education-news/michaelgove-held-talks-with-iq-genes-professor-8876500.html [retrieved 20 Jan 2020]

9. https://www.theguardian.com/society/2019/may/24/ivf-couples-couldbe-able-to-choose-the-smartest-embryo [retrieved 20 Jan 2020]

10. https://ghr.nlm.nih.gov/primer/therapy/ethics [retrieved 20 Jan 2020]

11. https://www.nature.com/articles/d41586-018-06784-5 [retrieved 20 Jan 2020]

12. Middeldorp, C.M., Hammerschlag, A.R., Ouwens, K.G., GroenBlokhuis, M.M., Pourcain, B.S., Greven, C.U., Pappa, I., Tiesler, C.M., Ang, W., Nolte, I.M. and Vilor-Tejedor, N., 2016. A genome-wide association meta-analysis of attention-deficit/hyperactivity disorder symptoms in population-based pediatric cohorts. Journal of the American Academy of Child \& Adolescent Psychiatry, 55(10), pp.896-905.

13. Stergiakouli, E., Martin, J., Hamshere, M.L., Heron, J., St Pourcain, B., Timpson, N.J., Thapar, A. and Davey Smith, G., 2016. Association between polygenic risk scores for attention-deficit hyperactivity disorder and educational and cognitive outcomes in the general population. International journal of epidemiology, 46(2), pp.421-428.

14. Ladikas, Chaturvedi, Zhao, Stemerding, Ladikas, Miltos, Chaturvedi, Sachin, Zhao, Yandong, and Stemerding, Dirk. Science and Technology Governance and Ethics : A Global Perspective from Europe, India and China. 1st Ed. 2015. ed. Cham: Springer International : Imprint: Springer, 2015.

15. Zeiler, Kristin, E. Furberg, G. Tufveson, and Stellan Welin. "The Ethics of Non-heart-beating Donation: How New Technology Can Change the Ethical Landscape." Journal of Medical Ethics 34.7 (2008): 526-29.

16. Kline, P., 2013. Intelligence: The psychometric view. Routledge.

17. Plomin, R., 2019. Blueprint: How DNA makes us who we are. Mit Press.

18. Sternberg, R.J. and Grigorenko, E.L. eds., 2002. The general factor of intelligence: How general is it?. Psychology Press.

19. Neale, M.C.C.L. and Cardon, L.R., 2013. Methodology for genetic studies of twins and families (Vol. 67). Springer Science \& Business Media.

20. Bush, W.S. and Moore, J.H., 2012. Genome-wide association studies. PLoS computational biology, 8(12), p.e1002822.

21. Witherspoon, D.J., Wooding, S., Rogers, A.R., Marchani, E.E., Watkins, W.S., Batzer, M.A. and Jorde, L.B., 2007. Genetic similarities within and between human populations. Genetics, 176(1), pp.351-359. 
22. Moodie, J.E., Ritchie, S.J., Cox, S.R., Harris, M.A., Maniega, S.M., Hernández, M.C.V., Pattie, A., Corley, J., Bastin, M.E., Starr, J.M. and Wardlaw, J.M., 2020. Fluctuating asymmetry in brain structure and general intelligence in 73-year-olds. Intelligence, 78, p.101407.

23. Davis, O.S., Haworth, C.M. and Plomin, R., 2009. Learning abilities and disabilities: Generalist genes in early adolescence. Cognitive neuropsychiatry, 14(4-5), pp.312-331.

24. Dickens, W. T. and Flynn, J. R. (2006) 'Black Americans Reduce the Racial IQ Gap: Evidence From Standardization Samples’, Psychological Science, 17(10), pp. 913-920

25. Asbury, K. and Plomin, R., 2013. G is for genes: The impact of genetics on education and achievement (Vol. 24). John Wiley \& Sons [nb: The authors do not mention race].

26. https://www.bbc.co.uk/programmes/b042q944 [retrieved 20 Jan 2020]

27. https://www.theguardian.com/science/2015/mar/01/racism-sciencehuman-genomes-darwin [retrieved 20 Jan 2020]

28. http://ewanbirney.com/2019/10/race-genetics-and-pseudoscience-anexplainer.html [retrieved 20 Jan 2020]

29. https://www.roughtrade.com/gb/adam-rutherford/how-to-argue-with-aracist [retrieved 15 Jan 2020] - nb: as this book has not yet been published/was not published at the time this paper was written, it cannot be included in this paper's criticism of SR2.0. It is referenced in this short paper because 30 (below) is described in the source as flagging the book and was given the same title by the book's author.

30. https://www.youtube.com/watch? $v=$ cYf-xNsIb2I [retrieved 20 Jan 2020]

31. 28 , para $3 ; 30$

32. $27 ; 28 ; 30$

33. https://inews.co.uk/news/education/ethnic-minority-children-missinggrammar-school-places-racially-biased-11-plus-537548 [retrieved 20 Jan 2020]

34. Gillborn, D (2010) Reform, racism and the centrality of whiteness: assessment, ability and the 'new eugenics', Irish Educational

Studies, 29:3, 231-252

35. $30,1.08 .27$

36. Hayek, F; (1942); "Scientism and the Study of Society (Part One)"; Economica, Vol. 9, No. 35 (Aug), pp. 267-291

37. Hayek, F; (1943); "Scientism and the Study of Society (Part Two)"; Economica, Vol. 10, No. 37 (Feb), pp. 34-63

38. Hayek, F; (1944); "Scientism and the Study of Society (Part Three)"; Economica, Vol. 11, No. 41 (Feb), pp. 27-39

39. Popper, K., 2005. "The logic of scientific discovery". Routledge (first pub 1959).

40. https://www.bbc.co.uk/news/uk-50870309 [retrieved 20 Jan 2020]

41. Gillborn, D et al (e. ds); Critical Race Theory in education; 2018: Routledge;

42. Neville, H.A., 2008, Tynes, B.M. and Utsey, S.O. eds., Handbook of African American psychology. Sage Publications. 
Eric Joyce's doctoral thesis, due 2020, argues for ethical rules to govern the application of genetic research to education. He is a former chair of the UK parliament's all party group on Education. This paper is a shortened version of a thesis chapter dealing with the use by some scientists of social and popular media rather than scholarly publications. 